\title{
1
}

\section{Introduction: Sustainability Science as Co-Creative Research Praxis}

\author{
Alex Franklin
}

\section{Introduction}

The conception of this book has been guided by three inter-related aims. The first is to encourage reflection and debate on the relationship between collaboration and creativity ('co-creativity') within sustainability science research. The second aim is to support researchers in actively promoting and nurturing, but also managing and responding to, the effects of co-creativity within their research. The third is to better understand the potential of engaged and co-creative scholarship in furthering transformative sustainability agendas. Clearly, these aims are underpinned by a number of beliefs, including: that creativity and collaboration are co-present within sustainability research, that the two do and 'should' go hand-in-hand in the design and practicing of transformative research, and that a transformative agenda is central to much

\footnotetext{
A. Franklin $(\varangle)$

Centre for Agroecology, Water and Resilience (CAWR), Coventry University, Coventry, UK

e-mail: alex.franklin@coventry.ac.uk
} 
of the sustainability sciences. Also, though, that the pursuit of engaged scholarship and co-creative research as a form of praxis requires further critical consideration within the context of the sustainability sciences.

This chapter is primarily concerned with introducing the concept of co-creativity. The term is applied here in reference to both individual methods and overarching research approaches that seek to engender collaborative and creative forms of action and reflection. In the case of collaboration (i.e., the 'co-' of co-creativity), this signifies the prioritization given throughout this book to researching 'with' (rather than on, or for); in its broadest sense, it also acknowledges the fundamental relationality of life. A relational lens, and therefore also the notion of emergence, is similarly central to how creativity is itself conceptualized. The term creativity is understood here as embodying a generative way of thinking and being, seeing and doing, arising from relational forms of knowledgepractice. An extended discussion of this conceptualization is provided below.

In fusing together collaboration and creativity into the concept of cocreativity, what I and all other contributors to this edited collection are especially interested in is socially inclusive research. Whilst at its base, all scientific scholarship is arguably creative, the degree to which individual research studies purposively aim to achieve greater social inclusivity through their chosen methodologies varies widely. By placing emphasis on social inclusivity in our conceptualization of co-creativity, this in turn highlights the political nature of a question that frames the entirety of this collection: how can co-creative research practice, as a generative process, best support the emergence of alternative-potentially even transformative-ways of being in the world?

Thus, methods and approaches are understood here as co-creative when they stimulate alternative understandings of why and how things are, and how they could be. Notably, though, such stimulation of alternative understandings needs to be a shared one, experienced (albeit in different ways and to different extents) by multiple persons within a research process, including both the 'researchers' and the 'researched' alike. To engage in co-creative research therefore calls for a retained sensitivity to the importance of researching 'with' throughout the process of 
doing research. Furthermore, in order to realize transformative sustainability agendas through the stimulation of alternative understandings of why and how things are, and how they could be, such alternative framings are simultaneously critical in tone. More particularly, by offering up co-creative ways of 'mobiliz[ing] the critique through the alternative-by showing that another way is possible' such methods and approaches help 'call in to question' not only how things are, but also the way in which we, or others, commonly respond to them (Hannah \& Jeremijenko, 2017 , p. 214). This in turn accounts for why co-creativity is directly associated through this collection with engaged scholarship.

Approached as a form of praxis, engaged scholarship is accordingly understood here as being driven not simply by a desire to interpret and understand the world, but also to change it (Cowley, 2013). Materializing such a desire requires a close and continuous alignment of thought and action: that is, it requires 'the synthesis of theory and practice and the reciprocal relationship between them' (Cowley, 2013, p. 1). All the chapters in this collection are authored by scholars committed to such a praxis-orientated form of engaged scholarship. At the same time, nevertheless, the relative umbrella coverage of the term engaged scholarship is also visible throughout (Boyer, 1990, 1996; Shultz \& Kajner, 2013). Indeed, the array of cases presented in this book are variously informed by (but not limited to) principles of Participatory Action Research (see for examples Chapters 4, 8, 12, 13, 16), Militant Scholarship (see especially Chapter 3), Appreciative Enquiry (see especially Chapter 5), Care-full Scholarship (see Chapters 5 and 16) and Transformative Research (see for example, Chapters 6,12 and 14). In their own way, each of these serve as exemplars of engaged scholarship. Collectively, in turn, they also provide a good indication of the diverse ways in which co-creativity, in association with engaged scholarship, is able to shape and enrich not only the sustainability sciences, but also the value that comes from taking the time to critically consider and reflect upon the complex nature of its contribution.

In parallel to noting the relative diversity of research approaches featured within this collection, it is nevertheless important to also acknowledge that the individual research methods are themselves all drawn from the social sustainability sciences. That is, their primary 
orientation is towards deepening our understanding and advancement of sustainability by questioning its social and cultural origins, meanings, practices, values, interpretations, structures, systems and relationships. This shared characteristic can be situated within, on the one hand, an appreciation by all the contributing authors for the vast array of epistemologies and ontologies circulating within the sustainability sciences, but also, on the other hand, a critical awareness of the ongoing dominance of more traditional and often very binary forms of problem framing. In response, whilst this edited collection is not intended as an attack on more traditional forms of research scholarship in and of themselves, it is aimed at further drawing attention to what Sandercock and Attili (2012, p. 140) eloquently summarize as:

the many other ways of knowing that exist: experiential, intuitive and somatic knowledges; local knowledges; knowledges based on the practices of talking and listening, seeing, contemplating and sharing; and knowledges expressed in visual, symbolic, ritual and other artistic ways.

Moreover, it is particularly aimed at explaining how these many other ways of knowing might care-fully (Moriggi et al., 2020) and respectfully be enrolled, through co-creative forms of engaged, transdisciplinary scholarship.

To delineate this collection one step further, the type of social sustainability science with which it can be affiliated (as akin to the aforementioned definition of engaged scholarship as a form of praxis) is one that regularly 'places power at the centre of analysis' (Eubanks, 2012, p. 229). Indeed, whilst an ambition to advance transformational research agendas is widely shared by sustainability scientists (Kates, 2011), reflective of both a traditional orientation towards (and ongoing dominance of) the natural and technical sciences, all too often scholarship within the sustainability sciences fails to engage with the political core of sustainability. In failing to pose the question of what a more just sustainable world would look like in a far more inclusive, dialogical and expansive manner, or, to acknowledge the political underpinnings of 'sustainable development' - and indeed why both just sustainability and sustainable development remain so elusive-this in turn not only brings into doubt 
the appropriateness of solutions being proposed, it also impedes diagnosis of the very problems that need to be addressed (Carpenter et al., 2020; Miller et al., 2014). In short, the emergence of just and sustainable forms of transformative change are all too regularly severely curtailed (Vallance et al., 2011). It is this curtailment that the co-creative and engaged forms of scholarship endorsed within this collection seek to overcome. It is also worth emphasizing, however, that what follows is not an uncritical collection of celebratory accounts. Rather, a unifying characteristic of this entire collection is the belief that the intentional nurturing of co-creativity through research practice, holds as much potential to be mutually rewarding for all involved as it does to be highly problematic. It is in recognition of this problematic that the need for extended critical reflection by a community of engaged scholars, and in turn the aims of this book, were originally derived.

Having offered some introductory orientation to what this book is about, as well as the beliefs and assumptions on which it is based, the remainder of this chapter is structured as follows. In the next section I briefly explain more about the original motivation behind this book. This serves to further set the scene for the interest of this entire collection with sustainability as requiring just and transformative change. I then look in greater depth at the meaning of creativity, and in turn, the nurturing of co-creative methods and approaches within the sustainability sciences. I end by offering an introductory overview to each of the chapters that make up the remainder of this collection.

\section{'Making a Difference': Transformative Research Agendas}

Throughout my career I have observed that when doctoral research candidates are asked during recruitment why they are interested in undertaking a doctoral degree within the sustainability sciences, many provide an answer that is primarily centred around an inherent desire to make the world — or at least a small part of it—a more just and environmentally sustainable place. Whilst a doctoral research project is perceived (either in the short or longer term) as a means of achieving this goal, 
the desire to contribute new knowledge commonly remains secondary, occasionally even requiring a prompt in order for it to be mentioned at all during the initial interview. Such aspirations for making a 'real world' difference through one's doctoral research come in many different shapes and forms. Sometimes, for instance, they are heavily prioritized around a single issue, sometimes around multiple issues; sometimes they engage with the social, cultural, environmental and economic pillars of sustainability in intentional concert; in other cases, they are orientated almost exclusively towards one pillar alone. Similarly, sometimes they are seemingly driven by an ambition, or a need, to bring about change at a global scale; other times the motivation-no less powerful-is about achieving change locally in a particular place, or with a particular group of individuals. Another commonly reported ambition, both personally and professionally, is that a scientifically robust connection be established between the research and the change that the individual is seeking to bring about. In parallel, much greater recognition is increasingly being given to the importance of the research process itself, as well as-or in some cases even instead of - aspiring to any sort of pre-definable direct and immediate end result.

It has been my sustained encounter with this deeply felt need by doctoral candidates for 'making a difference'-for engaged scholarship in all its various forms - and alongside, the questions and responsibilities that my colleagues and I are then necessarily confronted with as doctoral supervisors, mentors and coordinators of sustainability science research projects, which ignited my own motivation for editing this book. Such questions include: actually, how synergistic are the institutional requirements of contributing new knowledge, and the personal desires for making a 'real world' difference, within the regulated space of a doctoral degree? To what extent, regardless of the relative breadth or narrowness of the above stated ambitions, can a difference be made (outwith academia) through doctoral or early career stage research? Or perhaps even more to the point in this context, how to go about trying to achieve this whilst at the same time meeting the scholarly and institutional demands of the associated academic research without detriment to the wellbeing of the researcher (including their work-life balance)? And, relatedly, what impact will it have on the morale of the researcher should 
they decide, part way through, that they are unable to make sufficient difference within the lifespan of the $\mathrm{PhD}$ ? Furthermore, on the part of a supervisor or mentor, what are the best ways to support such ambition, including during the occasions when the scholarly, institutional and 'real world' demands are tending more towards being in conflict rather than synergy with one another?

In seeking through this edited collection to provide some answers to these questions, the approach taken is one that forefronts the firsthand accounts of the contributing authors' own direct experience of co-creative research practice. Notably also, the majority of the chapters are centred around research undertaken during a Doctorate. Such experiential accounts serve to richly evidence and support the critical reflections of the authors on what is involved and what is encountered when it comes to propagating co-creativity in the pursuit of transformative research. Moreover, it is hoped that the centrality given to first-hand accounts will assist the reader in relating to and subsequently building upon the learning shared by the authors in their own future research practice. In this respect also, the book has been written with a primary target audience in mind of doctoral and early career researchers affiliated to academic institutions, but also researchers working out-with academia across a range of different institutions and community settings. At the same time, though, it is hoped that the relatively wide range of disciplinary backgrounds, plus the international profile and experience of contributors, will make the collection insightful and relevant to a much broader cohort of co-creative sustainability and transdisciplinary practitioners and research mentors.

When compared to the project based short-termism that characterizes much academic research, the relative freedom of a social science doctoral research contract, plus the opportunity it commonly presents for at least three years of focused study, is in many ways more conducive to facilitating societal change. Moreover, a driving ambition to bring about change can actually be one of the best reasons for an individual wanting to embark on a $\mathrm{PhD}$ in the sustainability sciences. This view is built on observing (and personally relating to) the importance, the essentialness, for research encounters to have meaning not only for the research participants, but also for the researcher. That the actions and beliefs of 
people and communities might otherwise merely constitute or represent 'data' to be collected or 'extracted', is not enough-verging even, for some researchers, on being unethical. For it is the meaningfulness of research encounters, particularly those of a deep and/or sustained nature, that sparks the potentiality for change and gives energy to the need for action.

Furthermore, given the reality that only a small minority of those we engage with through our research practices are likely to come into direct contact with the research findings, it is the contact-the collaboration - that we have with them during and through the research process itself that is sometimes the chance to stimulate a change in mindsets and in practice. It is also the encounter itself that creates an immediate opportunity to acknowledge and in turn celebrate the work of many research participants, through shared recognition of their commitment to making a difference, or simply their daily struggle to overcome the micro, meso and macro level injustices of our unsustainable systems and institutions. This is particularly so for those individuals whose voices otherwise remain silenced or marginalized; but equally also for those who are driven by the ambition to change the thinking and ways of working amongst people in positions of power whose voices already get heard.

Therefore, it is my-our-contention through this collection, that dedicated time must be set aside to dwell, to reflect, on the transformational potential that comes from the process of 'doing' and 'being' engaged through one's research and with all those contributing to the research (for further discussion on this see for example Chapters 3, 5, 12, 13 and 16). It is also my contention that conceptualizing engaged scholarship as a form of co-creative praxis and, in turn, exploring co-creativity from a political starting point of engagement and inclusivity, can be of mutual reward to the practicing of both. With this in mind, as a further introduction to the chapters contained in this collection, but also more immediately as an orientation for the remainder of this chapter, three guiding questions are hereby proposed:

o What does it mean to think of research as a co-creative practice and of researchers as co-creative practitioners?

o How can engaged forms of co-creative research practice be nurtured? 
o Why does attending to the (inherent) co-creativity of research matter within the sustainability sciences?

Responding to these questions and building also on the opening discussion, in the next section I offer a brief overview of the trajectory of academic debate concerning the meaning of creativity. In turn, I then further explain how co-creativity is conceptualized for the purposes of this collection.

\section{Conceptualizing (Co-)creativity as Relational and Emergent Praxis}

As a subject of study creativity, scholarship dates back to at least the nineteenth century. It is only since the late twentieth century, though, that it has really burgeoned as a field of scientific interest (Kaufman \& Glăveanu, 2019). In the vast majority of the material published prior to the twenty-first century, a few overarching observations can be made; observations that, in turn, explain why it is only actually a relatively narrow stream of creativity scholarship, published during the last two decades or so, that directly informs the aims and research questions guiding this book. The first of these observations relates to how creativity has traditionally been defined; the second relates to the prevailing unit of study.

The standard definition of creativity, which has dominated its study from within the field of psychology since at least the 1950s (Runco \& Jaeger, 2012), points towards the bringing into being of something new and useful. Under this definition, creativity can take the form of a thought, an action or an object, with the utility component generally depicted as representing at least some degree of 'social value' (see, for example, Helfand et al., 2016). Somewhat surprisingly, much of the wider body of creativity scholarship merely accepts and runs with this basic definition. Where substantive critique does exist, it is rightly centred around the connection that this dual emphasis on novelty and utility establishes with capitalist market pressures for the production of new and valued commodities (Liep, 2001). As Rehn and De Cock assert, 
for example, 'emphasis on novelty is needed to ideologically position creativity as part of an economic movement and to connect it to the modernist ideology of progress' (2008, p. 225).

In terms of the implications of such a definition for the future of creativity itself (or indeed, its relevance to the transformative agenda of this edited collection), the risks include that creativity comes to be nurtured within educational and institutional contexts merely with the intention of preparing individuals for securing 'competitive advantage over others in a world dominated by the need to achieve and accumulate' (Literat \& Glăveanu, 2016, p. 330). Furthermore, as Chan (2016, p. 649) explains, in an institutional environment in which novelty is held in increasingly high regard, including attracting tangible rewards, it is likely that over time 'novelty will permeate the assumptions, perceptions, attitudes, values and methods of workers in this field'. The point being made here is that rather than serving to increase creativity, such emphasis on novelty or innovation instead merely creates 'a discourse of novelty' and 'a rhetoric of experimentation' (Chan, 2016, p. 649). Alongside this perceived erosion of creative substance, Rehn and De Cock raise further critique on the grounds that:

We cannot allow the concept of creativity to be always-already defined by novelty, nor to fall under the ideological framework of progress and modernism $[\ldots \ldots]$ The notion of novelty as defining creativity is [...] not only analytically problematic, it is also uncreative as it discounts other possibilities. (Rehn \& De Cock, 2008, p. 225).

In the context of academia particularly, such critique rightly raises the need for considerable scepticism and caution when it comes to responding to the seemingly ever increasing institutional endorsement for heightened evidence of creativity in scientific inquiry; an endorsement that commonly serves only to create the above stated limitations of an over emphasis on novelty. This is a point that Leitheiser et al. discuss in much greater depth in Chapter 2 of this collection (including from an early career perspective). More broadly, being an implicit point of concern for all contributors to this collection, it is also the reason why this book should not be read as an unqualified celebration of the presence 
and furthering of co-creativity within research practice. At the same time, though, as I return to later in this chapter, neither is it a reason for one to ignore nor dismiss the idea that attending to the (inherent) co-creativity of research practice matters within sustainability science research.

Running in parallel to the traditionally widespread acceptance of novelty and utility as being the defining components of creativity, common also to much of the existing creativity literature, has been an overriding concern with the individual as a unit of analysis; or more specifically still, the individual mind. Such an extended and prolonged degree of concentration on the individual has been attributed by some to a modernist preoccupation with an ideology of individualism. Reflective and reinforcing of this trend, is the fact that the vast majority of creativity scholarship derives from the field of cognitive psychology. Accordingly, discerning, modelling and defining the characteristics of a creative individual has tended to attract by far the most attention, including in particular investigation of the types of thinking and corresponding personality traits most supportive of generating creative ideas. ${ }^{1}$

Despite a scholarly interest in the working of the human mind continuing to dominate creativity research, there exists a growing cohort of researchers who regard the prevalence of this focal point as problematic:

If there are some unifying features for the psychology of creativity that cut across the whole domain they unfortunately group around the more or less implicit belief that it is the individual mind doing the creating. (Glăveanu, 2014, p. 7)

Beyond the perceived over-emphasis placed on the individual, also contributing this critique, is a growing dissatisfaction with the tendency for much of the early scholarship to actively project and uphold an image of the creative individual as being that of the [predominantly male] genius, of eminent creators who almost singlehandedly revolutionize society and culture' (Glăveanu \& Sierra, 2015, p. 345). Such a conceptualization, as Glăveanu and Sierra argue at length, 'is ultimately

\footnotetext{
${ }^{1}$ Attributed with stimulating much of this line of scholarship is Guilford (1950) and his work on divergent thinking. For a review of numerous models of creativity as being the property of the individual, see Kaufman and Glăveanu (2019).
} 
used as a political tool to silence the claim to creativity and agency of the marginalised or oppressed' (p. 345).

Whilst more recent scholarship has largely rejected the idea that 'true' creativity is the property only of eminent individuals, its replacement with the idea that creativity resides 'within' all of us is not itself entirely unproblematic either (Glăveanu \& Sierra, 2015). As Literat and Glăveanu (2016, p. 330) explain, for example, the danger here is that for those of a neo-liberalist persuasion especially, 'creativity becomes not only an individual trait, but an individual responsibility-everyone is required to cultivate his or her own creativity'. Upon this reading, by being conceived as something that we 'should' all be meeting and living up to, this in turn implies a failing of ourselves as individuals should it be discerned that we are not constantly striving to attain (ever more) exceptional standards of practice (see Chapter 2 for an extended discussion of this point). That this book does not inadvertently add to this pressure is something that has been afforded considerable thought during its compilation. Crucially, as I discuss further below, the call for the cocreative potential of research practice to be more actively nurtured is one that goes hand-in-hand with the importance of ongoing critical reflection and of an ethics of mutual care (Hartz-Karp \& Stocker, 2013).

As a consequence of the prolonged interest in the role of the human mind, two further characteristics discernible within much creativity scholarship are a general propagation of the Cartesian mind-body divide, and a discounting (or even denial) of the fundamentally relational nature of our lives. Indeed, it was not until the latter stages of the twentieth century that the social dimension of creativity began to receive greater attention, albeit with the research foci initially limited merely to investigating the effect of environmental conditions on the creativity of an individual (see e.g., Amabile, 1996; Nickerson, 1998). As Glăveanu (2010) recounts, the limitation with much of this initial discussion of what came to be termed 'social creativity' (see also Purser \& Montuori, 2000), is that by 'portraying the social as an external environment, a set of stimulations that facilitate or constrain the creative act', this in turn obscures the 'social roots' and 'social dynamics' of creativity (p. 83, original emphasis). 
It is only in the last two decades that, in some areas of the creativity research field at least, a growing momentum can be observed, away from solely individualistic understandings of creativity and beyond binary notions of 'external' environmental influences. The alternative conceptualization of creativity being proposed is a relational and emergent one, understanding creativity as residing in collaborative forms of knowledgepractice. It is this conceptualization (and the largely complimentary variants thereof) that has proved influential in refining how creativity, and in turn also co-creativity, is understood for the purposes of framing this edited collection. Particularly noteworthy here are the contributions of Tanggaard $(2012,2015)$ on 'sociomaterial creativity', and the considerable body of work offered up by Vlad Glăveanu and colleagues on 'distributed creativity' (see also Sawyer \& DeZutter, 2009; Sawyer, 2006, 2018; Ingold \& Hallam, 2007).

Tanggaard (2012, p. 20) posits sociomaterial creativity as a means of promoting 'awareness of how different environments in everyday life do not merely [in]form creativity and create conditions for it, but also themselves represent a substantial component of creativity'. As she explains, 'creativity thus occurs when we develop our practices-not via isolated thought processes but as part of life itself' (Tanggaard, 2012, p. 22). Meanwhile, in considerably extending and deepening his own earlier conceptualization of creativity as simultaneously 'I/he/we' (Glăveanu, 2010), ${ }^{2}$ Glăveanu (2014), puts forward the notion of distributed creativity. The term 'distributed' signifies a conceptualization of creativity "not as a "thing" but as action in and on the world' (p. 9 [original emphasis]), and accordingly, as being located not in the essence of an individual, but rather 'in-between people and objects' (2014, p. 9). As such, '...creative action is distributed between multiple actors, creations, places and times' (p. 2). Moreover, as Glăveanu (2014) goes on to explain, creativity is 'never simply distributed as an end state but always in the process of being distributed' (p. 9).

In accordance with both Tanggaard $(2012,2015)$ and Glăveanu (2014) (see also Glăveanu, 2015, Glăveanu et al., 2019; Sawyer, 2006,

\footnotetext{
2 Furthering also the work of such as Negus and Pickering (2004); Potts et al. (2008); Sawyer and DeZutter (2009); Vygotsky (2004)
} 
2018; Sawyer \& DeZutter, 2009; Ingold \& Hallam, 2007), creativity is understood in this book as a relational and emergent activity that is anchored in social practice. Notably, though, as Glăveanu himself is careful to point out, such an understanding is meant as 'an argument against individualism, not the individual' (Glăveanu, 2014, p. 9 (emphasis added)). Rather, the intention here is to move the discussion 'from the individual to the collective' - the latter including both human and non-human form-without 'losing the individual component from sight' in the process (Glăveanu, 2015, p. 191). It is by moving the discussion away from creativity as an essence, as derived purely from thought, or as a fixed state of achievement, that it becomes possible to understand it as a collaborative practice, a relational state of doing, being and becoming. Such an understanding is encapsulated well in the concept of distributed creativity.

Therefore, it is the concept of distributed creativity that directly informs the meaning attributed to co-creative research practice here (and similarly also it's potential for nurturing transformative change). At the same time, however, by conceptualizing co-creative research as a socially inclusive (and embodied) form of praxis, founded on the notion of researching with, and bringing co-creativity into contact with the notion of engaged scholarship, this serves to reinforce the political edge of cocreativity; a key dimension that is otherwise not always so apparent within existing scholarship on distributed creativity. The installation of a political lens, in turn, also helps to guard against any ongoing potential for propagating the misuse, or 'dark side' of creativity within the sustainability sciences-a point I return to below.

\section{Research as Co-Creative Praxis}

In this section, I argue that the value of a co-creative lens rests not in its use for categorizing individual research methods as either co-creative or not, but rather in understanding why it is possible to locate or install a potential for co-creativity in a multitude of research methods and approaches across the sustainability sciences. In doing so I not only 
account for the current absence of the term 'creativity' from much scientific discourse on research methods, but also why it matters that we bring it back to the fore. Indeed, notwithstanding a long and widely acknowledged relationship between scientific discovery and creative thinking (albeit propagated in part by the sustained emphasis on the eminent creative individual), the presence and role of creative practice in 'fieldwork' has tended to receive far less attention (although for some notable exceptions see e.g., Carpenter et al., 2020; Kara, 2015; Pauwels \& Mannay, 2019).

The relative silence as to the role of creativity in such primary research settings in part reflects a history of science dominated by calls for objectivity and replicability. It also reflects a tendency towards conservativeness when it comes to the construction of what constitutes 'rigorous research' within any one discipline. Parallels can be drawn here with Lubart's (1998) broader reflection that 'culture encourages creativity in some situations and for some topics but discourages it for others' (p. 342). That creativity is either seldom referred to by name or explicitly promoted within standard research methods texts across most of the sciences is, perhaps, far more of a reflection of the culture of mainstream academic research practice, than it is an indicator of its actual presence and influence throughout the research process. As Kaufman and Glăveanu (2019, p. 3) put it: 'creativity is everywhere and nowhere in academia'.

Given the still very much dominant belief that scientific enquiry, as an exclusive professional domain, is ultimately dependent on the expertise of the professional scientist alone, it is perhaps predictable that even less attention has in turn been given to the idea of research as $c o$-creative practice; that is, as being simultaneously creative and collaborative in nature. Despite some clear exceptions (e.g., PAR, transdisciplinary science), all too commonly within academia, 'the results of creativity are celebrated as more or less individual achievements' (Tanggaard, 2012, p. 21). The expertise, rigour and diligence with which an individual researcheror even a whole team of researchers-plans, collects and analyses their data, is obviously central to the eventual standard of a research project. However, the value and significance of the findings are as much related to the contributions of the research participants, as to the researcher 
themselves. ${ }^{3}$ As such, whilst the researcher commonly plays a key role in analysing, interpreting and recording findings, the eventual outputs are in many senses theirs alone in name only. ${ }^{4}$

If, however, in accordance with the above stated conceptualization of distributed creativity, research practice is instead approached as a relational process of 'engaging in shared creation', often with the result of conceiving something, in thought or in deed, that a researcher would not otherwise arrive at on their own (Lubart \& Thornhill-Miller, 2019, p. 286), this begins to give it a very different emphasis. When research practice is perceived relationally in this manner we are all simultaneously researchers and research participants (see e.g., Chapters 3 and 16 this book). As Glăveanu et al. (2019, p. 2) summarize: 'even when working in solitude, we implicitly build on and respond to the views, knowledge, and expectations of other people'. It is therefore the need to encourage further critical reflection on the shared and collaborative nature of creativity within research practice, towards which this chapter (and this entire collection) seeks to contribute through its conceptualization of 'co-creativity'.

A rich and diverse literature already exists on the societal and scientific gains that can simultaneously be achieved through the adoption of appreciative, participatory, decolonial and action research orientated principles of engaged research (see e.g., Chapter 4, this book). Nevertheless, there remains much more to be understood about the relationship between creativity and collaboration in the furthering of transformative sustainability agendas more broadly throughout the sustainability sciences. The same argument applies equally when it comes to conceiving what constitutes a creative research method. Attention needs to be directed not to the properties of a method in isolation, but rather to its use in a way that encourages participants to think openly and differently. Accordingly, co-creative methods are not understood here as necessarily limited to those that are overtly recognizable as either collaborative (e.g., PAR,

\footnotetext{
${ }^{3}$ For an example of where this has been creatively acknowledged see Kinpaisby-Hill Mrs C. (2008). Taking stock of participatory geographies: Envisioning the communiversity. Transactions of the Institute of British Geographers, 33(3), 292-299.

${ }^{4}$ This detail being, of course, highly significant, as the attribution by name creates a sense of ownership and reinforces the privileging of the individual scholarly voice.
} 
transdisciplinary science) or creative (e.g., art-based methods of enquiry) by design. Building on this opening clarification, and responding also to the second and third of the guiding research questions set out above, the next section therefore proceeds to discuss how co-creative research encounters might best be nurtured in a way that offers those involved the time and space to think differently; that is, to help generate alternative understandings of why and how things are and how they could be.

\section{Nurturing Co-Creative Research Encounters}

Kara (2015, p. 1) asserts that 'doing research is an inherently creative activity at all stages of the process'. As much as this accords with how I conceptualize creativity here, it is nevertheless important to also acknowledge that, in practice, considerable variation occurs in the ways in which creativity features, or is invoked, during periods of data collection. We can likely all, for example, recall moments in the process of data collection that, regardless of how standard the research method, have produced intensely inspiring sessions of creative and visionary thinking; similarly, we have also all likely experienced occasions of exposure to creative techniques that have failed to produce within us, or within other participants around us, anything remarkable at all (for further discussion of this see especially Chapters 12 and 13, this book).

As Axinte reflects upon (Chapter 12, this book), just because a research activity is designed to induce a creative encounter, or might widely be thought of as an overtly creative technique, this does not mean that it is experienced as such by the participants. Why is this? Understanding how the introduction of more overtly creative methods might be received and responded to by research participants forms a crucial part of preparing an approach that is capable of opening-up rather than closing-down the potential for co-creativity. What are the effects, for example, of confronting particular sets of citizens with a more overtly creative method or approach? Is there a danger that too innovative, alternative or very artful forms of creativity might alienate or act as a barrier to the participation of some in the research? How can those who wrongly 
perceive themselves as 'not creative' best be supported in engaging with more overtly creative research activities in a more rewarding way (for further discussion in a policy context, see also Chapter 16, this book)?

In unpacking the reasons for and effects of this variation in terms of how either more or less overtly creative methods might be received and responded to by participants, my interest here is in the possibilities that can arise from making researchers more conscious of their (potential) role as enablers of co-creativity. However, as explained above, in encouraging an increased awareness of the role and presence of co-creativity within the research process, this is not meant to imply a subsequent (nor universal) need for making its presence more explicit by way, for instance, of utilizing only more overtly creative research methods in sustainability science research. Creative methods can (and do) include the use of a rich array of overtly creative techniques, tools and other prompts designed to enable and encourage people to think and act differently from how they perhaps otherwise normally would in their everyday lives (see e.g., Chapters 14 and 15, this book). At the same time, though, there is also much potential for co-creative research practice to be nurtured through the use of more traditional social science research methods.

I am reminded here of a piece of advice given by the author Rebecca Giggs during a recent writing workshop. She explained that the purpose of structure is to enable you to be creative with the content. When creating an argument through a piece of written work, the role of structure is to support, not to overpower (Giggs, 2020). Beyond its value in guiding the process of academic writing, wider lessons can be drawn from this example when it comes to thinking about how best to nurture the co-creativity of others in a research setting. This includes, for instance, the context of encouraging community members to participate in research activities they might otherwise find challenging (see Chapter 5, this book for further discussion on the parallel role of carefull scholarship). As noted by Davies et al. (2013, p. 85) 'the provision of "safe" structure' enables people 'to take risks, to think creatively and critically, and to question'. It supports the establishment of a research environment in which the participants-or co-researchers-'feel that their contributions are valued' (Kligler-Vilenchik \& Literat, 2018, p. 77). 
Demonstrating to research participants that they are being listened to and heard on their own terms can, however, be more or less attainable with some methods as compared to others. In conceptualizing and encouraging the nurturing of co-creative research practice, prioritization is given in this collection to offering examples of whole approaches, but also individual methods, tools and techniques that embrace a high degree of openness in the shaping of how a participant is able to engage and respond (Sawyer \& DeZutter, 2009; Tanggaard \& Juelsbo, 2016). Another characteristic shared by all such examples is that they are centred around a desire to achieve meaningfulness and inclusivity, rather than innovativeness or originality through research encounters (see e.g., Chapters $3,4,5,11,12,13$ and 14). Prioritizing a meaningful encounter for the participant does not, of course, negate the importance of an original contribution to knowledge as remaining at the heart of academic research. Rather, it is by attending to the encounter in such a way that it creates and retains meaning and integrity for the participants, as well as for the researcher, which in turn gives rise to originality. ${ }^{5}$

To return once more to existing theories of creativity, in putting forward the dual ideas of distributed creativity and collaborative emergence, Sawyer and DeZutter (2009) suggest a group of collaborating individuals to be an ideal setting from which creativity can emerge. Within this setting, the most fertile conditions for its emergence are said to be where there is sufficient openness retained in the process to allow for at least a degree of 'unpredictability' and 'improvisation', as well as 'moment-to-moment contingency' (p. 82). Parallels can be drawn here with more open and unstructured forms of traditional social sciences research methods, as well as more visually and materially creative research methods (many of which are derived from the arts and humanities). Similarly, Tanggaard's (2012) call for much greater attention to be given to the sociomaterial dimensions of creativity accords well with the range of methods documented in this collection. This is true with regards to both the participatory and material components around which they are variously aligned. In the case of the latter, for example, as Tanggaard

\footnotetext{
5 Originality, conceived in this way, in turn avoids an over reliance on its acknowledgement and legitimation as such being solely at the determination of academia.
} 
asserts: 'a material can be regarded creative in its confrontation with people, who respond to the object's hardness, its softness, or whatever the object can do for them' (2012, p. 24). As a direct illustration of this, the creativity that emerges from areas such as deep mapping (see Chapters 11 and 12, this book), or community theatre (see Chapter 13), is no more located in the cognitive domain of a singular 'creative individual' than it is solely attributable to the creativity of humans alone- 'the creativity of our imaginative reflections is inseparable from our performative engagements with the materials that surround us' (Ingold \& Hallam, 2007, p. 3, cited in Tanggaard, 2012, p. 24).

In all of the above such cases, the interaction between the researcher and the researched is not adversely overly scripted from the outset, but is rather left very much open, allowed to find its own natural rhythm and thread. Along similar lines (albeit outside of a research setting), Sawyer (2018) uses the example of improv theatre to illustrate the productiveness of ambiguity in a collective encounter:

As a result of unpredictability and ambiguity, even a performer doesn't know what his own creative action means. Only when the interaction continues does the meaning of a single action become clear. Performers trust the collective creativity of the group to determine their own action's meaning. (p. 284)

Not entirely dissimilar to the above example of improv theatre, the fact that academic research commonly requires advanced planning and careful forethought, does not need to foreclose the possibility of spontaneity (see e.g., Chapters 9, 15, and 16, this book). A retained willingness on the part of the researcher to deviate from the script, to seek ways of enlivening it (Hitchings, 2012), or on occasion to ignore the script entirely - if, in the actual moment, there is felt to be value in doing so- is an integral part of approaching primary research as an inclusive, emergent and situated form of practice (for further examples of this, see Chapters 3, 8 and 12, this book). The fact that this is rarely acknowledged, or reflected upon, in the process of securing ethical approval, says far more about the institutionalized nature of the ethical approval than the enactment of research itself. 
From this perspective, then, knowing how to investigate an issue in situ is as much about the way in which a researcher approaches, presents and guides the performance of a particular method during a research encounter, as it is about the appropriate selection of the individual method itself. At the same time, exploring and remaining open to the possibilities of collaboration requires a deep acceptance of, but also the active making-of-room for the inherent unknown potential and richness of social interaction. Similarly, on the part of a research supervisor too, equipping the researcher with the ability (both mentally and emotionally) to accept as necessary the occasional occurrence of 'mess and stumbling' in the situated unfolding of research as an emergent social practice is crucial (Tanggaard \& Juelsbo, 2016, p. 86). It is as important for their ability to 'become with' their research participants, as it is for a supervisor to 'become with' their student (Haraway, 2007).

Both the planned and the actual emergent meaning(s) and experience of a research encounter, can be equally as significant in shaping the researcher and the research participants' potential for co-creativity. This point is well evidenced by Moriggi (Chapter 5, this book) in her framing and practicing of arts-based creative methods through Appreciative Inquiry and an ethics of care. Her account helps to further illustrate, for instance, why transdisciplinary forms of scientific enquiry, when practiced as a form of care-full scholarship (Moriggi et al., 2020), offer such a strong foundation for nurturing co-creative research practice in and of itself. At the same time, it also evidences why 'slower' and more open forms of research enquiry can be particularly conducive to co-creative thinking, in which the time and space is made available for the researcher to understand from the perspective of the participant; and for the participant-if not to understand from the perspective of the researcher-to at least become more consciously self-aware of their own perspective (see also e.g., Chapters 6 and 16, this book).

Much is known about the potential negative effects of participating in scientific research and correspondingly the ethical steps that need to be adhered to in order to prevent any adverse effects. In contrast, little attention is commonly given to the positive impacts of a research encounter upon individual participants. More overtly co-creative techniques, such 
as photo-voice (see Chapters 9 and 13, this book) and guerrilla narrative (see Chapter 3, this book), for example, can also be understood as having the potential for much more dispersed and distributed forms of meaning making (see also Chapter 4, this book). As spaces for care-full reflection (Moriggi et al., 2020), they can enable insight into practice that in turn allows the participants-researchers and researched aliketo envision how to further enhance or otherwise change their approach and activity at a wider scale or in alternative settings. At the same time, as sites of embodied meaning making, more needs to be understood about how the visceral and material experiences of research participation themselves support deeper reflection, insight and self-awareness during, but also beyond, individual research encounters (see e.g., Chapters 5, 6 and 16 , this book). The importance of co-creative research practice is in this sense by no means limited to the findings that are subsequently generated and shared by the researcher; it also retains the potential to contribute to the wider transformative goals and aspirations of sustainability science. In short, (co-)creative moments tend to be very memorable; in turn, as Pearson discusses in much greater depth (Chapter 6, this book) memorable moments possess an on-going potential to be birth places for transformative change.

Creating the time and space for research participants to reflect on their own existing practice, to bring into conscious thought that which is already known, including as a means of supporting their own selfevaluation of their actions and achievements to date, can play a direct role in shaping future actions. This is another sense in which the doing of research practice, in and of itself, retains the potential to be co-creative. Indeed, sometimes evidence of co-creative thinking and action becomes immediately apparent within research practice, whilst on other occasions its emergence is much slower and far less linear. Also relevant here is the connection drawn by Tanggaard (2012; see also Vygotsky, 2004, Wegener \& Wegener, 2016) between continuity and renewal: "ways of doing" already in the world are taken as starting points for new creations' (p. 20). As she points out, bringing about change in practice is not necessarily always a pre-mediated or even conscious act. Rather, realization and critical reflection around the fact that an action has brought about a change in conditions can often follow behind. On occasion, for example, it is 
only by momentarily stepping out of the daily routine to participate in, for instance, a qualitative research interview, that an individual is able to dwell on what they have been 'doing' and acknowledge for themselves what has (or has not) thus far been achieved (see, e.g., Chapters 8, 13 and 16 , this book, for further discussion of this point in connection with specific individual methods).

Somewhat ironically, the above avocation for research methods that favour relatively low levels of structure and high levels of openness, stands in marked contrast to the ways in which the subject matter of creativity has itself predominantly been investigated. For many scholars of creativity, as a reflection of its strong disciplinary base in psychology, rigorous research is largely framed by the need for 'control and representativeness' (Mayer, 1998, p. 456). The result has been a dominance of psychometric and experimental research approaches, together with a preference for quantitative forms of research and analysis. Presumably, however, as and when a distributed understanding of creativity comes to be accepted more widely within this field, so too might the value and robustness of more qualitative, ethnographic and transdisciplinary forms of research practice.

To summarize then, nurturing creativity within research can involve both tangible and intangible elements of creative design. Similarly, creativity can be implicit or explicit in what is asked of participants, and research exercises can range from activities that are relatively mundane to those that might be thought of as far more extraordinaire. As such, cocreativity can either be an integral component of a traditional research method, or it can require that such a method be turned on its head and turned inside out. Ultimately, though, whilst some methods may lend themselves more easily to advancing the co-creative potential of research practice, the realization of this potential resides as much in the process of doing research and being engaged, as in the actual components of a particular method. When practiced reflexively and sensitively, a vast array of research methods can (and do) invoke co-creative thought and action. As noted above, but worthy of repeating: it is because of this framing of co-creativity that we do not limit ourselves in this collection to restricting the categorization of methods as creative to those that are more overtly recognizable as such by design. Nor do we attempt to construct a list of 
which methods are, or are not, co-creative in their composition. Doing so would be misguided at best. ${ }^{6}$ Rather what we are most interested in here is nurturing and enabling the realization of co-creativity through the very potential of the research encounter.

\section{Co-creativity and the Transformative Potential of Sustainability Science}

If engaged scholars are to transform the social world for the purposes of equality, they need to be examining questions and concerns that are directly relevant to the everyday lived experiences of excluded individuals and communities, questions which emerge from their own ontological understandings of what it means to be in the world. This is the basis from which changes in the structures, systems, and relations that underpin social exclusion can emerge. Thus, the focus is not just on what is known and what scholars and communities can know together, but also who they can become together. (Kajner, 2013, p. 16)

Akin to Kajner's (2013) above call with respect to engaged scholarship, if an ambition of the sustainability sciences is to make the world a better place, socially, economically and environmentally, then opportunities for increasing the contribution of academic research need to be sought, including through the pursuance of adaptive and transformative change. An underlying aim of this book is to advance understanding of the role and potential of co-creative research practice in furthering such agendas. What has been referred to elsewhere as the contemporary obsession with creativity can, however, on occasion, create an environment in which individuals feel under considerable pressure to act creatively (Weiner, 2000). This, and a wider context referred to by Rehn and De Cock (2008) as an era in which 'creativity has been corralled into the service of both big business and the nation state' (p. 229) (see above; see also Chapter 2, this book), raises the question of how to go about nurturing

${ }^{6}$ Including, also, for the fact that what might be received as highly creative in some disciplines may be viewed as entirely standard or even mundane in others. 
and attending to co-creativity in the sustainability sciences without inadvertently suppressing the very voices (human and non-human) most in need of being heard.

Alongside the challenge of retaining integrity of research practice in the face of adverse external pressures to 'be' creative, there is, of course, also a 'dark side' of creativity that also needs to be acknowledged. Much has already been written about this in relation to both the 'creative individual' and the disastrous societal, environmental and economic impact of some creative ideas and actions (see, e.g., Cropley et al., 2010; Glăveanu et al., 2019; Chapter 2, this book). There is no doubt far more to be understood and discussed in this context with regards to the misappropriation also of co-creative research methods. Whilst the analysis of specific such examples and cases falls without the scope of this chapter, in this penultimate section I nevertheless take the opportunity to make some concluding comments about why it matters that the presence and potential of co-creativity is critically reflected upon within sustainability research especially. In short, I am driven here by the conviction that, despite its risk of being (further) co-opted by elite interests, this does not and cannot negate the potential contribution of co-creativity to achieving more just and empowering forms of transformative change (Carpenter et al., 2020). For this potential to be realized, however, it has to be practiced in a mutually ethical and integral way (Moran et al., 2014), or as Moriggi argues (Chapter 5, this book), it needs care-full scholarship.

Creativity, when understood as distributed, requires of us that we 'continuously construct ways of connecting with others and understanding them, including as a means of understanding ourselves' (Lebuda \& Glăveanu, 2019, p. 4). Participatory and transdisciplinary forms of action research inquiry can be particularly effective in facilitating such mutuality of co-creative thinking between self and others through the very process of doing research. Seemingly pivotal to their effectiveness is the importance they attach to dialogue (Giri, 2002; see also Chapter 3, this book). In direct accordance with a conceptualization of creativity as distributed, a greater emphasis on dialogue, as a means of better understanding the epistemologies and ontologies of one another and of others, would surely be of benefit to all forms of sustainability science research (Lin, 2011). 
It is through a shared understanding and appreciation for one another's differences in expertise, in perception and in life experience, that we are in turn able to advance our understanding about what matters and for whom, about how things are and for whom, about the reasons for why this may be the case, and about how they might be changed for the better (and of course, better for whom). Enabling others, and ourselves, to become better at thinking differently, thinking passionately about how things could be, rather than merely how they are and to what effect, is arguably crucial to making a positive difference in the world. Indeed, much of the importance attached in this collection to furthering our understanding of the co-creative potential of engaged scholarship, is motivated by the need to bring alternative ways of knowing and practicing into being. Towards this very goal and given also that all academic researchers have 'a social responsibility', 'using the concept of creativity critically and reflectively is [thus] crucial' (Glăveanu et al., 2019, p. 4 (emphasis added)). Moreover, this pairing of creativity and critical thinking ensures not only that we remain critical in our thinking about creativity, but also that we can advance our critical thinking through (co-)creativity. As Nickerson (1998), for example, makes clear, despite the widespread, erroneous tendency for creative and critical thinking to be contrasted as opposites to one another, they are in fact 'two sides of the same coin. Good thinking requires both and requires that there be a balance between their contributions' (p. 399); so too does engaged scholarship (MacKinnon, 2010).

Therefore, not only does this book aim to enable researchers to find co-creative ways of better understanding and interpreting what is going on around them and why this may be so, it is simultaneously also crafted towards assisting researchers to become more advanced in prompting others to think more critically, more creatively and more reflexively about their relationship with those around them (be they near or far; human or non-human). In follow-on, it asks about what actions can be taken to enhance or change that relationship in a forward looking manner. Indeed, when transformative change is framed in such a way, the dependence on this pairing of creative and critical thinking becomes even more obvious. As both Vygotsky (2004) and Vadeboncoeur et al. (2016) explain, whilst it is precisely human creative activity that makes 
the human being a creature oriented toward the future, creating the future and thus altering his own present' (Vygotsky, 2004, p. 9); simultaneously, 'it is creativity, and the human ability to see and act "other than" or "as if", to challenge and to question, that assists the creation of new practices along with the values that support them enabling the dialectic between continuity and change to become cultural transformation' (Vadeboncoeur et al., 2016, p. 300; see also e.g., Chapter 6, this book).

To conclude then, the ambition of 'making a difference' through cocreative research endeavour requires simultaneously both a clear strategy and a retained openness for the unknown and unforeseen. This in turn calls for an emphasis on iteration rather than linearity in the research process, a prioritization of dialogue, a sustained pursuit of self-reflexivity, an embracing of 'emotional, embodied and intuitive forms of knowing' (Shrivastava \& Ivanaj, 2011, p. 84), and simultaneously, an altogether greater recognition of the relational nature of research practice. The latter not only attests to the importance of caring for and with others, but also of self-care (Tronto, 1993). Indeed, to close this introduction by indulging in what Wegener and Wegener (2016) might term an act of creative mirroring (i.e., creativity as building on the richness of what already exists), I find it stimulating to end here by drawing once more from a feminist ethics of care perspective that implicitly underpins much of this discussion and combine it with an equally powerful lesson drawn from agroecology — a field of sustainability science that arguably leads the way in achieving transformative change. What they lead me to conclude is that, in realizing its potential to contribute to making the world a better place, co-creative research practice needs to be nurtured in a way that is 'political in its perspective and dialogical in its method' (Donovan, 2006, p. 324; see also Kajner, 2013; Hartz-Karp \& Stocker, 2013). By doing so, the (critical) pursuit of co-creative research in turn provides further momentum towards establishing sustainability science itself as simultaneously a science, a movement and a practice (Wezel et al., 2009). It is by adapting and pursuing sustainability science as such, that it stands the greatest chance of making a difference. I hand over, in a moment, to the contributing authors to propose and further explain some of the ways in which such guiding principles and ambitions might be taken up. 


\section{Introducing Co-Creative Research in Practice}

The remainder of this book comprises of predominantly first-hand accounts of research approaches, tools and techniques that are centred around openly (and actively) collaborative and creative forms of research inquiry. In some chapters, this comes with more of an emphasis on widening collaborative practice; in others, greater emphasis is placed on overtly stimulating creative practice. In all cases, though, whether involving explicitly or implicitly collaborative and creative techniques, the approaches and methods presented are understood as nurturing cocreative research practice, due to the inherently open, respectful and relational nature of their form.

In accordance with the aims and motivation guiding this book, all lead authors of the chapters that follow are early career (doctoral or postdoctoral) researchers. More specifically they are all advocates for —and actively engaging with-transdisciplinary and participatory methodologies, and are all working within the (social) sustainability sciences. Serving to further unite them as a community of practice at the time of writing is their involvement (either directly or indirectly) with a four-year H2020 Marie-Skłodowska Curie Innovative Training Network (MSCA-ITN) entitled RECOMS. Founded on principles of transdisciplinary science, the RECOMS consortium of early career research fellows, academic mentors and expert practitioners has a shared goal of advancing 'resourceful and resilient community environmental practice'.

A cross-cutting pedagogical theme of RECOMS is visual and creative research methods. That this project ever came to be formulated around this theme is testament to a wish to enable and encourage early career social sustainability scientists to experiment with more overtly creative research techniques. Creating the time, space and resources for such experimentation in a research setting that is centred around an international network of fifteen doctoral research projects (incorporating a relatively diverse range of empirical research settings and research questions) provides a major opportunity for critical reflection on the relationship between co-creativity, research practice and transformative change. This book is one of the outputs derived from this opportunity. I 
end this opening chapter with a brief introduction on each of the chapters that follow, and a note of explanation on how they connect to and interrelate with one another.

Chapter 2 serves to further introduce and provide a critical contextualization for the collection. Leitheiser et al. approach the uptake of creative methods from a starting point of neo-liberalization and the on-going trend for the corporate managerialism of university research. Beginning with an example from the dark side of creativity, they discuss how the creativity of scientific endeavour is simultaneously shaped and mediated by both individuals and institutions. In the case of individuals working in managerialist universities, however, they argue that the possibility of pursuing co-creative research praxis is commonly highly constrained and at constant risk of co-optation. Supported by examples, they explain why creative methods, as a collaborative form of research practice, have potential to reinforce or to subvert the relegation of universities to mere 'factories of knowledge production'. In offering a very critical analysis, and warning against 'forced creativity', they call upon academics to collectively reflect, with eyes wide open, on 'the possibilities for action' in order that creative methods might actually support, not merely further undermine, just transformative change.

Chapters 3, 4 and 5 are united in their emphasis on the significance of positionality in research and the need for conducting research in a way which directly challenges, rather than reinforces, imbalances in power. In Chapter 3, Ruiz Cayuela and Armiero consider their own positionality as militant researchers and the foundation that 'all knowledge production is partisan'. Having explained why it is essential that academic research challenges the homogenizing discourses of the elite, they then proceed to focus on the power of narrative and its potential for supporting more inclusive, transformative, and counter-hegemonic practices of research and knowledge exchange. They dedicate the remainder of the chapter to introducing and reviewing the use of guerrilla narrative as a mechanism for undermining the grip of capitalism by spreading 'commoning subjectivities' within marginalized communities. In doing so they offer a range of illustrations from their work with Co-operation Birmingham, a mutual aid organization located in the west midlands of the UK. Like Ruiz Cayuela and Amiero themselves, Co-operation Birmingham is 
committed to igniting social transformation through the disruptive practicing of co-operation, solidarity, horizontality and care, from the ground up.

In Chapter 4, De la Rosa Solano et al. explore the presence and uptake of decolonial participative approaches in the environmental humanities. Their analysis reaffirms the validity of people's knowledge in the construction of historical narratives. It also illustrates the just and transformative potential of environmental history research when practiced more inclusively, in conformity with the principles of decolonialism and Participatory Action Research. Drawing on a series of examples from the literature of Latin America, De la Rosa Solano et al. discuss at length the value of applying a decolonial lens to the environmental humanities. Such an approach, they argue, supports not only a better understanding of our relationship with the non-human, but also one's own positionality within the research process. Taking as a case in point the role of memory as an historical resource, De la Rosa Solano et al. explain why the centring of a decolonial lens achieves a more fair and inclusive process of knowledge generation. This, in turn, they conclude, further strengthens the contribution of environmental history to achieving societal transformation.

In Chapter 5 the geographical setting of just research practices moves from Latin America to northern Europe. Here, Moriggi explores the transformative potential of co-creative research methods by approaching them from a starting point of Appreciative Inquiry and an ethics of care. Taking the case of Green Care, she offers an extended reflection of her own doctoral research, undertaken in Finland, on nature-based activities with a social-innovation purpose. The Participatory Action Research approach employed by Moriggi enabled her to collaborate with three different communities of green care practitioners in a manner that paid equal attention to care-full research and to 'creativity, innovation and imagination as forms of knowledge production'. In offering a first-hand critical account of her use of five different kinds of creative and arts-based methods with members of these communities over an extended period of time, Moriggi illustrates how an 'ethos of appreciation' can be 'embodied and applied in practice' and to what effect. 
Chapters 6,7 and 8 all draw our attention to the connection between co-creative methods and arts-based research. In Chapter 6, beginning with the role of worldviews, interests, values and ideologies in shaping human behaviour, Pearson draws our attention to the potential contribution of artistic processes as a mechanism for triggering transformative change. Focusing in on these 'inner dimensions' of sustainability, she explores the transformative capacity of arts-based creative methods when it comes to supporting 'imaginative leadership' and 'transformative imagination' in the arena of sustainability. That is, how they might be used to 'provoke and strengthen' more environmentally conscientious 'transformative mindsets' through collaborative experimentation. The discussion is supported by a detailed account of two cases in which Pearson took a lead role in co-designing and implementing creative methods workshops with a range of different stakeholders. Orientated towards the more-than-human, the aim of the workshops was to stimulate deep selfreflection, as a means of opening up 'new spaces of possibility for action and perception'.

In Chapter 7, Van der Vaart begins with the question of 'how communities can be prepared - or prepare themselves - for a more sustainable future?'. In response, she reviews the opportunities that are created by bringing together science, arts and society, as part of a place-based transdisciplinary approach to enacting change. The chapter takes as its empirical focus a community arts project in the Netherlands, Grutte Pier, which was initiated by a social enterprise (PeerGrouP) specializing in the use of arts based participatory methods. In contrast to many of the other chapters in this collection, here co-creative methods therefore become the 'object' of the research enquiry. Drawing on data from indepth interviews with project participants, but also with local residents who chose not to engage with the project, Van der Vaart analyses the impact that such arts-based initiatives can have in promoting resourceful and resilient community environmental practice. Woven throughout this analysis, however, is a critical awareness of the inherent tensions and risks associated with measuring the societal value of arts-based practice.

In Chapter 8, in contrast to the approach taken by Van Der Vaart, Davis et al.'s discussion is centred around a first-hand reflective account of working with a community as a creative practitioner. With the 
'coming together' of academic researchers and art-based practitioners increasingly encouraged, this chapter is motivated by a perceived need for further critical methodological reflection on this pairing from a starting point of Participatory Action Research and the 'art of invitation'. Drawing on a case study from the north of the Netherlands, Davies et al. collectively reflect on the challenges of working within the conditions of an 'invited space'. Notably, this includes problematizing how to engage with, understand, and respond to the needs of a community on their own terms. They discuss the risk of instrumentalizing creative methods in accordance with external interests and the challenge that this presents, including with respect to their own personal ethics and integrity. Despite the inherent difficulties of coming in as an 'outsider', the chapters of Van Der Vaart and Davies et al. both nevertheless also attest to the opportunities that this status can sometimes bring. As Davies et al. explain, realizing this potential is ultimately dependent on the sensitivity and reflexivity with which arts-based co-creativity is practiced.

Whilst arts-based methods continue to feature in Chapters 9 and 10, here the focus is more firmly on visual methods. In Chapter 9, Leung begins by explaining her motivation to use the technique of photoelicitation in order to understand meaning making 'beyond word-based cognitive reflexivity'. In reflecting on her experience, she first focuses on using photo-elicitation as a means of softening the representational challenges of working in a cross-cultural setting within rural Japan, with a translator; and second, in response to a situation whereby her respondents-Japanese rice farmers - were neither well versed nor comfortable with providing extended amounts of verbal reflection. Notably, the photos in question are of rural artworks emplaced within the local farming landscape. Integral to Leung's account is the acknowledgement she gives to the importance, but also the difficulty, of interpreting how her respondents de-coded photographs in a way capable of encompassing 'the marked differences between Asian and Western cultures in the relations made between elements in an image'. In extending her exploration of such representational and cross-cultural challenges a step further, she also experiments with commissioning a local artist to create visual illustrations of oral quotations as an alternative form of translation. Leung's chapter therefore offers an openly critical account of the strengths and 
weaknesses of using creative techniques as a means of enabling crosscultural research practice. In parallel, it also encompasses the affective dimension of doing cross-cultural research.

In Chapter 10, the problematic of visual representation is also the focal point for Baimukhamedova, this time engaged in respect to media depictions of wild animals. Drawing on the example of Eurasian Lynx, Baimukhamedova traces the historical development of human-wildlife relationships within the Bavarian Forest region of Germany. In doing so, she offers a rich reflective account of applying visual analysis techniques to twentieth-century media publications as a means of understanding the affective quality of wildlife images. Beyond considering the overall importance of visual imagery when it comes to understanding societal relationships with the more-than-human, Baimukhamedova's account also attests to the need for visual material to be more closely attended to within social sustainability research more broadly. As she notes, whilst the applicability of visual analysis depends on the kind of research question one wishes to ask-some answers might well be found in the visual. Moreover, in learning to practice visual analysis, one is also propelled to reflect more intently on the positionality of their own gaze.

In Chapters 11-14, co-creative research practice is explored in the context of critical cartography. In Chapter 11, presenting creative mapmaking as 'transdisciplinary and conceptually boundless', Reitz explains how they enable the coming into being of alternative forms of 'sensing, representing and relating to space'. She evidences these assertions by offering a detailed account of two creative mapping methods: deep mapping and social cartography. In reviewing these two methods, Reitz discusses how they attempt to represent the complexity and open endedness of space in a way that is not possible with traditional cartographic methods. Notably, as she highlights, they bring to the fore a need to continuously ask of ourselves questions such as 'which ideas, senses, and values are included or excluded in the mapping process? Who is heard and who is silenced? What purpose does the map serve and which transformations can it unravel?' Beyond reminding us of the 'partial, subjective nature of map making', such questions demonstrate the revealing power of co-creative methods; a power that also extends 
to the role of methods such as deep mapping and social cartography in furthering the inclusiveness of social sustainability science research.

Deep mapping features again in Chapter 12, this time as part of a first-hand critical account of its use within an ex-industrial area of the Glasgow docklands (Scotland). Authored by Humphris et al., this chapter uses deep mapping to instigate an evocative conversation about the legitimacy of marginalized uses of 'discarded' places. Making optimal use of the 'thick description' that deep mapping affords, they weave together the rich layering of informal users and uses of their case study site-a site that, within traditional urban cartography, would otherwise be depicted as a vacant and derelict space. In doing so, Humphris et al. evidence and account for why co-creative arts-based practices, such as deep mapping, constitute valuable investigative tools. Through both their written and visual analysis, they demonstrate how deep maps can bring attention to place-making to better understand spaces, reshape relationships and support communities. However, in emphasizing the political nature of deep mapping, Humphris et al. simultaneously draw attention to the process of deep mapping as requiring a collaborative and reflexive cycle of research, dialogue, learning and action. It is through such a co-creative approach that the possibility of giving voice to 'marginalized micro-narratives' can best be realized. As Humphris' own personal critical reflection also shows, though, such a process must on no account be approached as unproblematic in and of itself.

In Chapter 13, whilst creative mapping remains at the heart of the research approach, here Anxite considers its potential as a digital method, in combination with photo-voice, for engaging young people in the planning of city-regions. Her chapter draws on doctoral research undertaken with young people residing in south-east Wales (the 'Cardiff cityregion'). Notably, this chapter demonstrates how co-creative methods can used as a means for stimulating dialogue around issues and concepts with which research participants may not otherwise be familiar, or appreciative of the relevance that they hold to their everyday (and future) lives and sense of place. Moreover, in electing to work with web-mapping and photo-voice, Anxite demonstrates how to stimulate such dialogue in a way that enables young people's views and aspirations for the future to be presented in a necessarily disruptive manner. At the same time, however, 
Anxite's account gives full acknowledgement to the limitations of what can be achieved - even with co-creative methods-when working in contexts of entrenched relationships of power and top-down decisionmaking. She also offers constructive reflections on the challenges of using visual and creative methods in group settings when working as a lone academic researcher.

In Chapter 14 Ramirez Aranda and Vezzoni further extend the discussion of digital participatory mapping that was initiated by Anxite in Chapter 13. In exploring the possibilities that digital tools offer for the achievement of 'more democratic and inclusive participation processes', they specifically consider the use of participatory mapping web apps as a means for facilitating decision-making around the planning, public use and protection of greenspace both locally and from afar. By way of illustration, they offer a technical account of the co-creation of two innovative online participatory GIS platforms ('My Green Place' (Belgium) and 'Greenmapper' (the Netherlands)). Whilst the examples given clearly demonstrate the potential value of digital methods in widening participation and challenging existing forms of accountable decision-making (both locally and at a distance), Ramirez Aranda and Vezzoni end with a series of critical reflections drawn from their first-hand involvement with these two cases. Notably, this includes guarding against the risk of digital participatory methods being taken up as a means of 'managing discontent through "artwashing". Whilst capable of making a strong contribution to transdisciplinary research, Ramirez Aranda and Vezzoni firmly categorize participatory web apps as a 'complementary tool', not a 'cure all'.

In Chapter 15 the importance of promoting co-creation as a basis for urban planning and policy decision-making is further considered in the context of grand challenges and 'wicked' environmental problems. Here, however, the focus for Rădulescu et al. is on Living Labs as a creative and collaborative planning method. Rădulescu et al. begin by offering a typology of Living Labs, based on an extensive review of the various ways in which they are interpreted and characterized within the current literature. Drawing also then on their own first-hand experience of involvement, they critically consider their potential for supporting the advancement of participatory practices within the domain of water 
infrastructure and spatial planning. Establishing planning as a fundamentally collaborative and inclusive form of practice, they argue, is essential to the future safeguarding of local environmental resources. Supported by a series of practice-orientated examples from three (past and present) water infrastructure projects in the Netherlands, the authors end by offering a series of recommendations for optimizing their use as a participatory planning tool.

In seeking to try and 'make a difference' through their research, commonly social sustainability scientists seek out the involvement of community groups, social movements, NGOs and/or marginalized or disempowered individuals as research partners. Less common is the active selection of private businesses or governmental institutions. As this collection evidences, though, there is sometimes as much to be gained from working with those who are otherwise depicted as being part of 'the problem'. In Chapter 16, Giambartolomei et al. offer an extended reflection on the dual challenges and rewards of engaging in transdisciplinary science where it involves a government institution, and where it constitutes the central pivot of a doctoral degree. At the same time, however, they argue for the potentially profound value of such a coupling when it comes to making a difference with one's research. Key here is the opportunity that such 'spaces in-between' present for outing the emotional and embodied dimensions of collaborative 'doing' transdisciplinary research. Drawing on Giambartolomei's first-hand experience of working with the Welsh Government, and supported further by a conceptual lens of care, the authors explain how more meaningful relationships between academics and policy-makers might be established and nurtured. In particular, they discuss the opportunities that transdisciplinary science creates for reinvigorating reflexive forms of governance and, in turn (in their research case at least), a willingness by governmental institutions to trial more (co-)creative and care-full forms of natural resources management.

The relationship between research and policy decision-making continues to be the main point of orientation in Chapter 17. In this final chapter of the collection, Zolyomi addresses the issue of how to make policy-makers take notice of, engage with, and act upon, the results of sustainability science research. Taking as a principal illustration the 
case of biodiversity loss, she pays particular attention to the contribution of creative methods when it comes to achieving policy impact. The discussion is supported by a review of existing literature and first-hand experience on how to go about communicating research findings at the European Union level. The experience is derived from working with a conservation and advocacy NGO. Zolyomi's account remains sensitive to the fact that very often a lack of financial resources further heightens the challenges that have to be confronted by researchers in order to be heard by policy-makers. Accordingly, alongside the role of creative methods she also pays close attention to the importance of message framing and to the channels of delivery. Zolyomi's work is driven by the conviction that understanding how best to communicate research to policy-makers is 'pivotal for a more sustainable future'. It is with this conviction and her accompanying reflections on how best to craft impactful messages that this edited collection is drawn to a close.

Acknowledgements This research received funding from the European Union's Horizon 2020 research and innovation programme under the Marie Sklowdoska-Curie Grant Agreement No. 765389.

\section{References}

Amabile, T. M. (1996). Creativity in context. Westview.

Boyer, E. (1996). The scholarship of engagement. Journal of Public Service and Outreach, 1(1), 11-20.

Boyer, E. (1990). Scholarship reconsidered: Priorities of the professoriate. Carnegie Foundation for the Advancement of Teaching

Carpenter, J., Horvath, C., \& Spencer, B. (2020). Co-creation as an agonistic practice in the favela of Santa Marta, Rio de Janeiro. Urban Studies, pp. 118

Chan, J. (2016). Creativity and culture: A sociological perspective, chapter 31. In V. P. Glăveanu (Ed.), The Palgrave handbook of creativity and culture research, Palgrave studies in creativity and culture (pp. 639-660).

Cowley, N. (2013). What is praxis? Discussed in relation to Hegel, Marx, Nietzsche and Sartre. Graduate and Post-Graduate E-Journal Volume 4, pp. 1-8 
(accessed April 28th 2021). https://www.waikato.ac.nz/_data/assets/pdf_ file/0005/149261/NatalieCowley.pdf

Cropley, D. H., Cropley, A. J., Kaufman, J. C., \& Runco, M. A. (Eds.). (2010). The dark side of creativity. Cambridge University Press.

Davies, D., Jindal-Snape, D., Collier, C., Digby, R., Hay, P., \& Howe, A. (2013). Creative learning environments in education-A systematic literature review. Thinking Skills and Creativity, 8, 80-91

Donovan, J. (2006). Feminism and the treatment of animals: From care to dialogue. Signs, 31(2), (Winter), 305-329.

Eubanks, V. (2012). Feminist phronesis and technologiesof citizenship. Chapter 11 In B. Flyvbierg, T. Landman, \& S. Schram (Eds.), Real social science: Applied phronesis (pp. 228-245). Cambridge University Press.

Giggs, R (2020, July 29). RECOMS training event 5-Writing workshop (Online training event).

Giri, A. K. (2002). The calling of a creative transdisicplinarity. Futures, 32, $103-115$.

Glăveanu, V. P. (2010). Paradigms in the study of creativity: Introducing the perspective of cultural psychology. New Ideas in Psychology, 28(1), 79-93.

Glăveanu, V. P. (2014). Distributed creativity: Thinking outside the box of the creative individual. Springer.

Glăveanu, V. P. (2015). Creativity as a social act. Journal of Creative Behavior, 49, 182-197.

Glăveanu, V. P., Hanson, M. H., Baer, J., Barbot, B., Clapp, E. P., Corazza, G. E., Hennessey, B., Kaufman, J. C., Lebuda, I., Lubart, T., Monuori, A., Ness, I. J., Plucker, J., Reiter-Palmon, R., Sierra, Z., Simonton, D. K., Neves-Pereira, M. S., \& Sternberg, R. J. (2019). Advancing creativity theory and research: A socio-cultural manifesto. The Journal of Creative Behavior, $0(0), 1-5$

Glăveanu, V. P., \& Sierra, Z. (2015). Creativity and epistemologies of the South. Culture \& Psychology, 21(3), 340-358

Guilford, J. P. (1950). Creativity. American Psychologist, 5, 444-454.

Hannah, D., \& Jeremijenko, N. (2017). Natalie Jeremijenko's new experimentalism. In R. Gruisin (Ed.), Anthropocene feminism, chapter 9 (pp. 197-219). University of Minnesota Press.

Haraway, D. J. (2007). When species meet. Post humanities series (Vol. 3). University of Minnesota Press.

Helfand, M., Kaufman, J. C., \& Beghetto, R. A. (2016). The four-C model of creativity: Culture and context, chapter 2. In V. P. Glăveanu (Ed.), 
The Palgrave handbook of creativity and culture research, Palgrave studies in creativity and culture (pp. 15-36).

Hitchings, R (2012). People can talk about their practices. Area, 44(1), pp. 6167.

Ingold, T., \& Hallam, E. (2007, red.). Creativity and cultural improvisation: An introduction. In E. Hallam \& T. Ingold (Eds.), Creativity and cultural improvisation (pp. 1-24). Berg.

Hartz-Karp, J., \& Stocker, L. (2013). Deliberative democracy, a collaborative action oriented learning process for a more sustainable future, chapter 9. In L. Shultz \& T. Kajner (Eds.), Engaged scholarship: The politics of engagement and disengagement (pp. 121-138). Sense Publishers.

Kajner. (2013). Beyond the binary Chapter 2. In L. Shultz \& T. Kajner (Eds.), Engaged scholarship: The politics of engagement and disengagement (pp. 9-20). Sense Publishers.

Kara, H. (2015). Creative research methods in the social sciences: A practical guide Policy Press.

Kates, R. W. (2011). What kind of a science is sustainability science? Commentary PNAS, 108(9), 19449-19450.

Kaufman, J. C. \& Glăveanu, V. P. (2019). A review of creativity theories: What questions are we trying to answer? In J. C. Kaufman \& R. J. Sternberg (Eds.), Cambridge handbook of creativity (2nd ed.) (pp. 27-43). Cambridge University Press. Accessed via https://www.researchgate.net/publication/334 749545_A_review_of_creativity_theories_What_questions_are_we_trying_ to_answer

Kligler-Vilenchik, N., \& Literat, I. (2018). Distributed creativity as political expression: Youth responses to the 2016 U.S Presidential election in online affinity networks. Journal of Communication, 68, 75-97.

Kinpaisby-Hill, M. C. (2008). Taking stock of participatory geographies: Envisioning the communiversity. Transactions of the Institute of British Geographers, 33(3), 292-299.

Lebuda, I., \& Glăveanu, V. P. (2019). Re/searching the social in creativity, past, present and future: An introduction to the Palgrave handbook of social creativity research, chapter 1 . In I. Lebuda \& V. P. Glăveanu (Eds.), Palgrave handbook of social creativity research, Palgrave studies in creativity and culture (pp. 1-9). Palgrave.

Liep, J. (2001). Introduction. In J. Liep (Ed.), Locating cultural creativity (pp. 1-13). Pluto Press.

Lin, Y.-S. (2011). Fostering creativity through education-A conceptual framework of creative pedagogy. Creative Education, 2(3), 149-155. 
Literat, I., \& Glăveanu, V. P. (2016) Same but different? Distributed creativity in the internet age. Creativity. Theories—Research-Applications, 3(2), 330342

Lubart, T. I. (1998). Creativity across cultures, chapter 17. In R. J. Sternberg (Ed.), Handbook of creativity (pp. 339-350). Cambridge University Press.

Lubart, T., \& Thornhill-Miller, B. (2019). Creativity: An overview of the 7C's of creative thought, chapter 15. In R. Sternberg \& J. Funke (Eds.), The psychology of human thought: An introduction (pp. 277-305). Heidelberg University Publishing.

MacKinnon, C. (2010). Engaged scholarship as method and vocation Catharine. Yale Journal of Law and Feminism, 22(2), 193-205. https://dig italcommons.law.yale.edu/yjlf/vol22/iss $2 / 2$

Mayer, R. E. (1998). Fifty years of creativity research, chapter 22. In R. J. Sternberg, (Ed.), Handbook of creativity (pp. 449-460). Cambridge University Press.

Miller, T. R., Wiek, A., Sarewitz, D., Robinson, J., Olsson, L., Kriebel, D., \& Loorbach, D. (2014). The future of sustainability science: A solutionsoriented research agenda. Sustainability Science, 9, 239-246.

Moran, S., Cropley, D., \& Kaufman, J. (Eds.). (2014). The ethics of creativity. Palgrave.

Moriggi, A., Soini, K., Franklin, A., \& Dirk, R. (2020). A care-based approach to transformative change: Ethically-informed practices, relational responseability, and emotional awareness. Ethics, Policy and Environment, 23(3), 281-298.

Negus, K., \& Pickering, M. (2004). Creativity, communication and cultural value. London: Sage Publications

Nickerson, R. S. (1998). Enhancing creativity, chapter 20. In R. J. Sternberg (Ed.), Handbook of creativity (pp. 392-430). Cambridge University Press.

Pauwels, L., \& Mannay, D. (Eds.). (2019). The SAGE handbook of visual research methods (2nd ed.). Sage.

Potts, J., Hartley, J., Banks, J., Burgess. J., Cobcroft, R., Cunningham, S., \& Montgomery, L. (2008). Consumer co-creation and situated creativity. Industry and Innovation, 5(5), 459-474.

Purser, R., \& Montuori, A. (2000). In search of creativity: Beyond individualism and collectivism. Paper presented at the Western Academy of Management Conference, Kona, Hawaii.

Rehn, A., \& De Cock, C. (2008). Deconstructing creativity, chapter 18. In T. Rickards, M. A. Runco \& S. Moger (Eds.), The Routledge companion to creativity. Routledge. 
Runco, M. A., \& Jaeger, G. J. (2012). The standard definition of creativity. Creativity Research Journal, 24(1), 92-96

Sandercock, L., \& Atilli, G. (2012). (Un)settling a settler society: Film, phronesis and collaborative planning in small-town Canada, chapter 8. In B. Flyvbierg, T. Landman, \& S. Schram (Eds.), Real social science: Applied phronesis (pp. 137-166). Cambridge University Press.

Sawyer, R. K. (2018). An interdisciplinary study of group creativity, chapter 18. In R. J. Sternberg (Ed.), Handbook of creativity (pp. 280-290). Cambridge University Press: Cambridge

Sawyer, R. K. (2006). Explaining creativity: The science of human innovation. Oxford University Press.

Sawyer, R. K., \& DeZutter, S. (2009). Distributed creativity: How collective creations emerge from collaboration. Psychology of Aesthetics, Creativity, and the Arts, 3(2), 81-92.

Shrivastava, P., \& Ivanaj, S. (2011). Transdisciplinary art, technology, and management for sustainable enterprise . Transdisciplinary Journal of Engineering \& Science, 2, 81-92.

Shultz, L., \& Kajner, T. (2013). Engaged scholarship: The politics of engagement and disengagement. Sense Publishers.

Tanggaard, L. (2015). Pathways, chapter 12. In V. Glăveanu, L. Tanggaard \& C. Wegener (Eds.), Creativity: A new vocabulary (pp. 96-103). Palgrave Macmillian.

Tanggaard, L. (2012). The sociomateriality of creativity in everyday life. Culture \& Psychology, 19(1), 20-32.

Tanggaard, L., \& Juelsbo, T. (2016). Mess, chapter 10. In V. Glăveanu, L. Tanggaard \& C. Wegener (Eds.), Creativity: A new vocabulary (pp. 78-86). Palgrave Macmillian.

Tronto, J. C. (1993). Moral boundaries. Routledge.

Vadeboncoeur, J. A., Perone, A., \& Panina-Beard, N. (2016). Creativity as a practice of freedom: Imaginative play, moral imagination, and the production of culture, chapter 16. In V. P. Glăveanu (Ed.), The Palgrave handbook of creativity and culture research, Palgrave studies in creativity and culture (pp. 285-305).

Vallance, S., Perkins, H. C., \& Dixon, J. E. (2011). What is social sustainability? A clarification of concepts. Geoforum, 42(3), 342-348.

Vygotsky, L. S. (2004). Imagination and creativity in childhood. Journal of Russian and East European Psychology, 42, 7-97.

Weiner, R. P. (2000). Creativity and beyond: Cultures, values, and change. State University of New York Press. 
Wegener, C., \& Wegener, G. (2016). Mirroring, chapter 11. In V. Glăveanu, L. Tanggaard \& C. Wegener (Eds.), Creativity: A new vocabulary (pp. 87-95). Palgrave Macmillian.

Wezel, A., Bellon, S., Doré, T., Francis, C., Vallod, D., \& David, C. (2009). Agreocology as a science, a movement and a practice: A review. Agronomy for Sustainable Development, 29, 503-515.

Open Access This chapter is licensed under the terms of the Creative Commons Attribution 4.0 International License (http://creativecommons.org/ licenses/by/4.0/), which permits use, sharing, adaptation, distribution and reproduction in any medium or format, as long as you give appropriate credit to the original author(s) and the source, provide a link to the Creative Commons license and indicate if changes were made.

The images or other third party material in this chapter are included in the chapter's Creative Commons license, unless indicated otherwise in a credit line to the material. If material is not included in the chapter's Creative Commons license and your intended use is not permitted by statutory regulation or exceeds the permitted use, you will need to obtain permission directly from the copyright holder. 